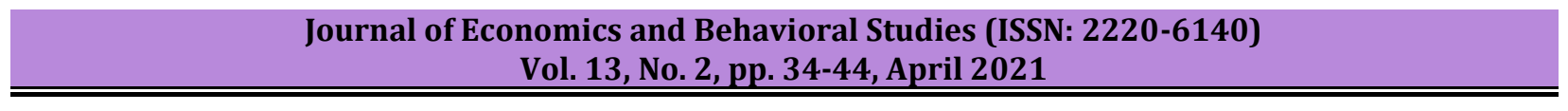

\title{
Integrating Approach to Build Customer Experiences: Lessons Learned from Mobile Customers in Ghana
}

\author{
Michael Boakye Yiadom, Madéle Tait \\ Nelson Mandela University, Department of Marketing Management, Port Elizabeth, South Africa \\ boakyeyiadommichael2016@gmail.com,madele.tait@mandela.ac.za
}

\begin{abstract}
Delivering a great customer experience is of paramount importance for any organization. The better experience customers have regarding the organization's products, or brands, the more repeat purchases and positive reviews they will receive. This paper explores the mobile mix as an integrated approach to facilitate a positive customer experience. A total of 415 respondents were selected and completed the survey through stratification and convenient sampling from 10 regions. The study adopted a positivistic paradigm and followed a quantitative research approach. The SPSS Amos 25 was utilized to analyze the collected data. The empirical results revealed that the mobile service mix has a significant positive influence and relationship with customer experiences. This paper provides relevant and practical recommendations that could increase positive customer experiences in the mobile industry.
\end{abstract}

Keywords: Experiential marketing, Customer experience, Mobile mix, Experiential mix, Mobile network operators, Ghana.

\section{Introduction and Background}

According to Schmitt (1999a), experiential marketers observe that customers are rational and emotional human beings primarily concerned about realizing pleasurable experiences. Customer experience (CX) consists of the dimensions of sense, feel, think, act and relate (Wibowo et al., 2021; Schmitt, 2010). The sense experience is connected with the senses and the experiences of customers through seeing, hearing, touching, tasting, and smelling (Conti \& Peachlivanidou, 2016; Wibowoet al., 2021). According to Schmitt (1999a) and Conti and Peachlivanidou (2016), the sense experience relates to the customer's sensory experiences, feel is the affective experiences and the creative cognitive experience is the think dimension. The physical experiences, behaviors and lifestyles of the customers constitute the act dimension. The social identity experiences resulting from relating to a reference group or culture refer to the related experience dimension (Gita, 2017; Ananta, 2016). In the context of this paper, customer experiences involve feelings and thoughts with regard to the rational, emotional, sensorial, physical and spiritual relations customers encounter with the people, processes and physical evidence of an organization. On the other hand, it refers to an organization's ability to create a sensory experience (sense), affective experience (feel), creative cognitive experience (think), physical experience, behavior and lifestyles (act) and social identity (relate). Effective and efficient implementation of customer experience programs could enable an organization to increase longterm sales and profit (Cuellar, Eyler \& Fanti, 2015).

The better experience customers have the more repeat purchases and positive reviews organizations receive, while at the same time reducing the friction of customer complaints and returns (Morgan, 2017). Customer experience is the defining competitive differentiator for organizations (Keiningham et al., 2020; Duncan, 2017). The customer experience concept has been applied and employed in several fields, including hospitality, online shopping, country branding and the airline industry (e.g. Conti \& Pechlivanidou, 2016; Grundey, 2008). However, little is known and there are no best approaches to building these experiences especially in the context of the mobile industry. Customer experience is being considered by researchers and marketers as alternative solutions to traditional marketing for achieving best results and organizational lifetime value (Shukla, 2007; Schmitt, 1999b). According to Danquah (2018), the limited emphasis placed on customer experience by organizations has denied them value for money. The lack of ideas in the creation of a positive customer experience is challenging a gap that needs to be solved to achieve the organization's objectives. In addressing this gap, research needed to be conducted to assist organizations to build a positive customer experience for a sustainable operation. A literature review is provided on customer experience, followed by a review on the mobile mix elements, and how to integrate it to build a positive customer experience. Next, the research methodology employed is discussed, whereafter the results are presented. Implications are presented and the paper concludes with recommendations for future research. 


\section{Literature Review}

Customer Experience: According to Kalbach (2016), experience as a term has no precise definition as it is holistic, personal and situational and could be positive or negative. The concept of experiences is defined from different perspectives. For instance, Sundbo and Darmer (2008) refer to it as a mental journey that provides customers with memories of having performed something special, having learned something, or having just had fun. The experience involves a customer's engagement in an activity that facilitates expectations and results in something memorable (Wibowoet al., 2021; Adhikari \& Bhattacharya, 2016). Experience functions as customers' personal source of information for the stories regarding their lives and are paramount for their self-perception (De Keyser et al., 2020; Mehmetoglu \& Engen, 2011). Customer experience (CX) involves the actions, thoughts and feelings over time, which is subjective and not objective from the perception of the individual and goes around the lenses of situations and circumstances (Kalbach 2016). According to Adhikari and Bhattacharya (2016), customer experience refers to the customers' engagement in activities that produce expectations and facilitates a memorable experience. Customer experience programs enable organizations to stimulate and facilitate customers' feelings of deep emotion towards marketed products/services/brands (Gao et al., 2021). Customer experience also enables organizations to market products or services to customers (Bricci, Fragata \& Antunes, 2016).

Customer experience consists of the dimensions of think, sense, feel, act and relate also known as experiential mix (Wibowoet al., 2021; Schmitt, 1999a) and experiential value namely, functional, emotional and social value (Farshad, Kwek \& Amir, 2012). The sense experience is associated with the senses and the experiences of customers through seeing, hearing, touching, tasting, and smelling (Wibowo et al., 2021; Krishna \& Schwarz, 2014). The think experience refers to creative and theoretical practices (Wibowoet al., 2021; Ananta, 2016) and the necessary intelligence that is required by an organization to create cognitive experiences and problem-solving through the creative involvement of customers (Gao et al., 2021; Alberg, 2014; Alkilani, Ling \& Abzakh, 2014). The feel experience relates to customers' inner feelings and emotions towards organizations, brands, products or services (Wibowoet al., 2021; Schmitt, 1999a, 2010). It involves the customers' mood and feelings towards organizations, brands and products (Datta 2017; Yang \& He, 2011). The feel experience could help an organization to provide customers with relaxation and excitement (Wibowoet al., 2021; Same, 2014). The act experience refers to the physical behaviors, lifestyles and interactions between an organization and customers (Conti \& Peachlivanidou, 2016; Schmitt, 2010). It helps to explore or change customers' behavior, lifestyles and social interactions with friends and communities through business offerings to facilitate positive experiences. The related experience combines the sense, feel, think and act experience dimensions to arouse positive customer experiences (Wibowoet al., 2021; Ananta, 2016; Conti \& Peachlivanidou, 2016).

Integrating Approaches to Build Customers' Experiences: Physical evidence (PE) or atmospherics involves the visual appeal and aesthetics of an organization (Amoah, 2016), as well as all non-living characteristics that exist during service encounters (Ullar \& Islam, 2011). Physical evidence refers to the organization's physical environment (i.e. ambiance conditions), spatial layout and functionality and signs, symbols, and artefacts (Yiadom, 2019). The physical environment provides the right environment and setting in order to facilitate a positive customer experience (Schmitt, 1999a). The organization's buildings, spatial layout and functionality involve the layout or décor of the organization's servicescape that should be designed to impact customers' perceptions of offerings (Jauhari \& Dutta, 2010). The spatial layout refers to the organization's arrangement, size and shape of machinery, equipment and furnishings, as well as the spatial relationships (Simpeh, Nasiru \& Tawiah, 2011). An organization's functionality concerns the ability of equipment in an organization to improve and enhance performance (Simpeh et al., 2011).

On the other hand, corporate branding refers to the signs, symbols and artefacts which contribute to the atmospherics of an organization (Smilansky, 2009). Signs are the organization's labels utilized for directional purposes (i.e. the entrances and exits) and to communicate rules of behavior (e.g. no smoking, or no eating at the hall) (Holttinen, 2014). According to Helen, Adrian, Martin and Moira (1999), the processes in an organization enable experiential value to be created for customers. Processes refer to "the way we do things" (Helen et al., 1999). Organizations must ensure that a thorough knowledge of the business processes is gained on time (Lin, 2011). The elements of processes in the mobile service mix include technology development 
(TD), research and development (RD) and machines and operations (MO). According to Gurel, Orhan and Fazil (2014), technology in an organization is utilized in the marketing of products and services. Positive customer experience could be created if an organization uses technology to organize and disseminate experience-oriented information amongst employees (Cambra-Fierro, Gao, Melero-Polo \& Trifu, 2021; Bilgihan, Cobanoglu \& Collins, 2014). According to Lacoma (2018), the success of research and development does not necessarily depend on the money that organizations invest in it, but rather on the practices, talents and innovations of their employees. On the other hand, machines and operations involve all the functions, procedures and people used in the transformation of inputs to final products (Ehlers \& Lazenby, 2010:123). The people mix includes input and output logistics (IOL), marketing and customer services (MCS), human resource management (HRM) and procurement managing (PM). Input and output logistics refers to how the organization receives stores and distributes inputs or raw materials for the product (inbound) (Ehlers \& Lazenby, 2010). Lovelock and Wirtz (2011) explain that an organization's output or finished goods are produced in a distinct factory with properly controlled and quality check systems. According to Ehlers and Lazenby (2010), customer services, which involve the installation, repair of phones and machines and training must be offered to customers when the need arises. The employees of the organization must be perceived as adding extra and advanced talents, skills and energy to the delivery of mobile (Bounds, Mallgee, Mayhew \& Van Deventer, 2011).

Primary Research Objective: Based on the variables and the hypothetical relationships indicated in Figure 1 , the primary objective of this paper was to empirically test the hypothetical model and the associated hypotheses. Further, this paper explores how organizations can utilize the mobile mix (i.e. physical evidence, process and people) as an integrating approach to build memorable customer experiences.

\section{Research Design and Methodology}

The main aim of this paper was to determine the integrating factors that facilitate the building of positive customer experiences for organizations. Figure 1 illustrates the hypothetical model.

\section{Figure 1: Integrated Approach to Build Customer Experience}

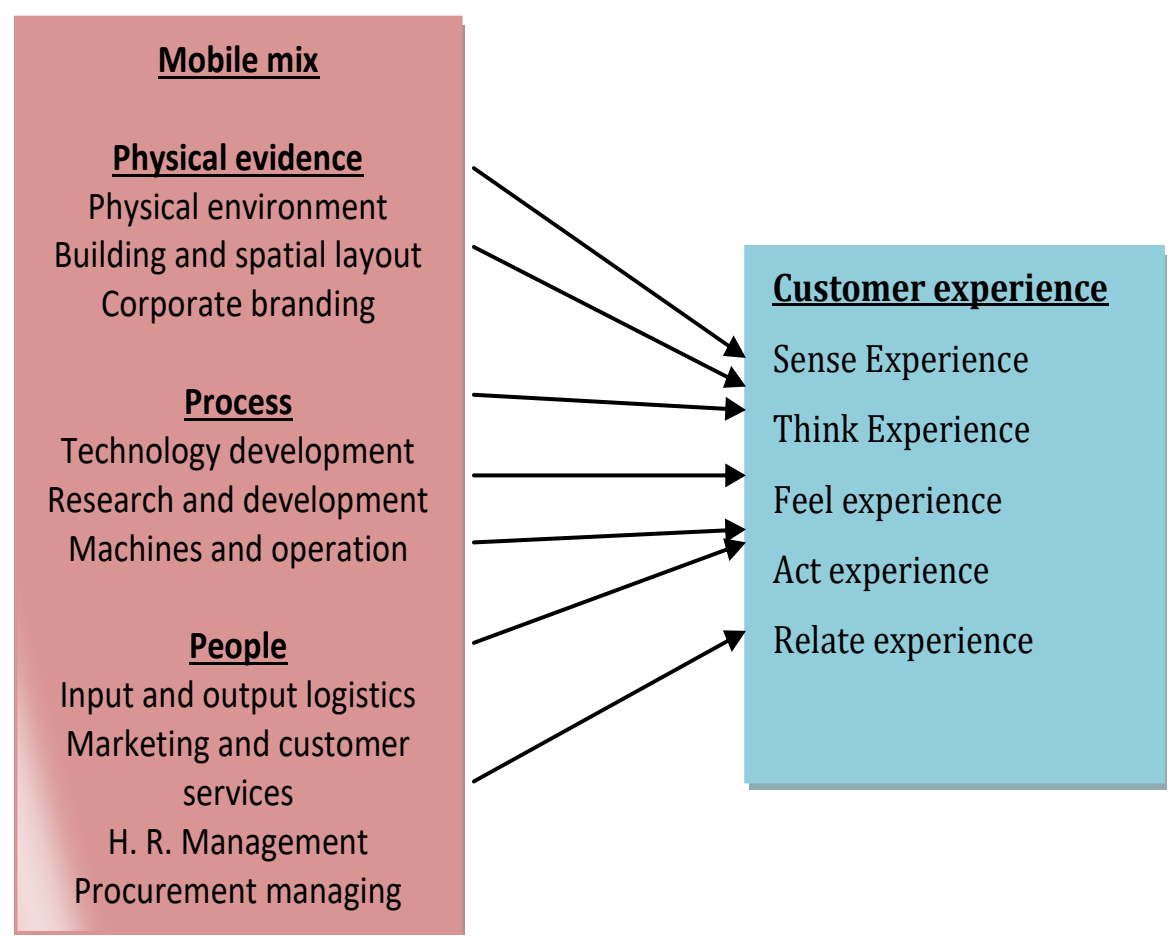


Based on the research objectives and the hypothetical model the following hypotheses have been formulated:

H1: There is a relationship between the physical environment and customer experience

H2: There is a relationship between building and spatial layout and customer experience

H3: There is a relationship between corporate branding and customer experience

H4: There is a relationship exist between technology development and customer experience

H5: There is a relationship between research and development and customer experience

H6: There is a relationship between machines and operations and customer experience

H7: There is a relationship between input and output logistics and customer experience

H8: There is a relationship between marketing and customer service and customer experience

H9: There is a relationship between human resource management and customer experience

H10: There is a relationship between procurement and customer experience

This research utilizes a quantitative research design. A positivistic paradigm was adopted and a quantitative approach was followed. Primary data for the study was obtained through self-administered structured questionnaires administered to respondents using stratified and convenience sampling. The sampling units recognized in this study involved the mobile network customers in Ghana. This sample was confined to the total number of voice subscribers for December 2018, which has approximately 40,934,875 customers spread across all 10 regions of the country, namely Ashanti, Brong Ahafo, Central, Eastern, Greater Accra, Western, Northern, Upper West, Upper East, and Volta (National Communications Authority, 2019). To ensure the proportionality of the sample out of the total population of 40,934,875 customers, the market share of the population for the individual network operators was identified proportionally. These involved: MTN $(20,092,798)$, Vodafone $(9,606,427)$, Airtel $(5,788,191)$, TIGO $(4,551,958)$, and GLO $(739,352)$. The calculations resulted in 49.1\%, 23.5\%, 13.33\%, 11.93\%, and $\%$ for MTN, Vodafone, Airtel, TIGO, and GLO, respectively. These individual samples resulted in a total of 384 participants for the survey. Additionally, using convenience sampling, a total of 31 customers at the premises of the mobile operators were added, representing a total of 415 participants. A five-point Likert scale ranging from "strongly disagree" (1) to "strongly agree" (5) was used. The IBM's Amos Version 25 web was utilized to capture data.

\section{Empirical Results and Findings}

This section presents the results of the empirical investigation undertaken.

Profile of Respondents: More males (52.5\%) than females (47.2\%) participated in the study. The majority of the respondents were individual customers (65.3\%), the rest were retailers $(10.8 \%)$, agents $(8.7 \%)$, wholesalers (8.4\%) and others (6.7\%). Most of the respondents were between the ages of 19 and $30(51.8 \%)$, the rest were between the following ages: 31 and 40 (25.3\%) 41 and 50 (17.1\%), and 51 and 59 (5.8\%). Also, over $94.9 \%$ of the respondents had formal and educational qualifications, with most respondents possessing a certificate/diploma/degree $(43.4 \%)$ or a high school certificate $(28 \%)$. The respondents mostly preferred MTN (50.4\%), Vodaphone (26.7\%), Airtel (12.3\%), Tigo (7.3\%) and then Glo (3.1\%). Out of the 10 regions, the majority of the respondents were from Ashanti (27.2\%), followed by Brong Ahafo (25.8\%), Greater Accra $(15.7 \%)$, Eastern (7\%), Central (6.5\%), Northern (5.1\%), Western (4.3\%), Upper West (3.6\%), Volta (2.9\%) and Upper East (1.9\%).

Validity and Reliability Analysis Results: A confirmatory factor analysis (CFA) was performed to test the relationship and impact between the mobile mix and customer experience (CX). For the researcher to check the influences and model fit through CFA, it must be noted that in an ideal situation, the Chi-square value should be insignificant or greater than 0.05 . Also, since the Chi-square statistic and associated p-values are highly sensitive to sample size, with larger sample sizes significant p-values can be derived even if a model fits the data (Hair, Black, Babin \& Anderson, 2014). In addition, the regression weights must be less than 0.05 or significant with the model fit indices depicting the following: CMIN/df $<=3, \mathrm{SRMR}<=0.08, \mathrm{CFI}>=0.95$, RMSEA $<=0.08$, TLI $=0.9 . \mathrm{A}$ CFA analysis on 10 items referring to the mobile mix and CX was performed using IBM's SPSS Amos Version 25. This resulted in CMIN/df=3.049, SRMR=0.0359, CFI=0.948, RMSEA=0.07, Chisquare value insignificant at $p=0.000, P G F I=0.684$, TLI $=0.939$, and Regression weights at $p=0.000$. These indicate that all of the CFAs were better than the required threshold together with SEM results for the Chi- 
square depicting a significant $\mathrm{p}=0.000$. Therefore the model was deemed fit. It must be noted that a Cronbach alpha value of 0.90 implies that $90 \%$ of the data is reliable. According to Saunders, Lewis and Thornhill (2016), an instrument is deemed reliable if Cronbach's Alpha is at least 0.7 for the questionnaire variables. The reliability coefficients of constructs were above the 0.7 threshold which is deemed significant.

Results of the Relationship Analyses: The results of the Pearson Product Moment Correlations [PPMC] indicated positive correlations between all factors. The mobile mix and customer experience (CX) indicated a strong positive correlation relationship amongst variables in the study ( $\mathrm{r}=0.816)$. The correlation relationship between physical evidence (PE) and CX dimensions were SE ( $\mathrm{r}=0.511)$, TE $(\mathrm{r}=0.531), \mathrm{FE}$ $(\mathrm{r}=0.524), \mathrm{AE}(\mathrm{r}=0.513)$ and $\mathrm{RE}(\mathrm{r}=0.451)$. The relationship between the mobile mix element physical evidence (PE) and the entire CX dimensions resulted in a strong value of $r=0.623$. It must be noted that, apart from the relationship between PE and RE which indicated a moderate correlation relationship, the PE and CX variables displayed a strong positive relationship in the study. Also, the mobile mix element process and CX dimensions showed the following relationships SE ( $r=0.568)$, TE ( $r=0.642), F E(r=0.609), A E(r=619)$ and RE $(\mathrm{r}=596)$. Therefore, there was sufficient evidence of construct validity and inter-item reliability of the questionnaire. In totality, the mobile mix element process and CX indicated a strong positive correlation relationship ( $\mathrm{r}=0.747)$. On the other hand, the element people in the mobile mix indicated a strong correlation relationship with the CX dimensions, with SE ( $\mathrm{r}=0.639)$, TE ( $\mathrm{r}=0.691)$, FE ( $\mathrm{r}=0.717)$, AE ( $\mathrm{r}=0.664)$, and RE $(\mathrm{r}=617)$.Also, a strong correlation relationship was found between the element people and CX with a value $r=0.820$. To justify and identify the correlation results statistically, as well as the goodness-of-fit of the model, structural equation modelling (SEM) was performed. The results for the SEM analysis indicated that the factors had a dual relation with each other and also significant. The model confirmed the goodness-of-fit with details involving CMIN/DF 3.049; SRMR 0.0359; and CFI 0.948, approximately at the required threshold of 0.95; RMSEA 0.07; PGFI 0.684; and TLI 0.939. The regression weight had a value of $p=0.000$ in all the hypothesized variables, and a standard scaled Chi-square $\left(x^{2}\right)$ measure of $p=0.000$ insignificant was established. This clearly shows that the Model met the required goodness-of-fit of the datasets. Therefore, there was a strong significant relationship between the mobile mix (i.e. physical evidence, process, and people), and customer experiences.

Based on the results of the correlation and the SEM analyses, hypotheses H1-H10 were all accepted as significant relationships were found between the following: there is a positive relationship between the physical environment and CX (H1), there is a positive relationship between building and spatial layout and CX (H2), there is a positive relationship between variable corporate branding and CX (H3), there is a positive relationship between technology development and CX (H1.4), there is a positive relationship between research and development and CX (H1.5), there is a positive relationship between machines and operations and CX (H1.6), there is a positive relationship between input and output logistics and CX (H1.7), there is a positive relationship between marketing and customer service and CX (H1.8), there is a positive relationship between human resource management and CX (H1.9), and there is a positive relationship between procurement managing and CX (H1.10). The empirical results from the study revealed that amongst the variables considered to have a positive influence on the experience of mobile network customers, with regards to the mobile mix elements, the building and spatial layout and physical environment in the physical evidence components were ranked highest with an estimate of $1.162, \mathrm{p}=0.000$ and 1.037, $\mathrm{p}=0.000$, respectively. Figure 2represents the relationship between the mobile mix and the experiential mix (CX) that was tested. 
Figure 2: Relationship between Mobile Mix and Experiential Mix (CX) Model

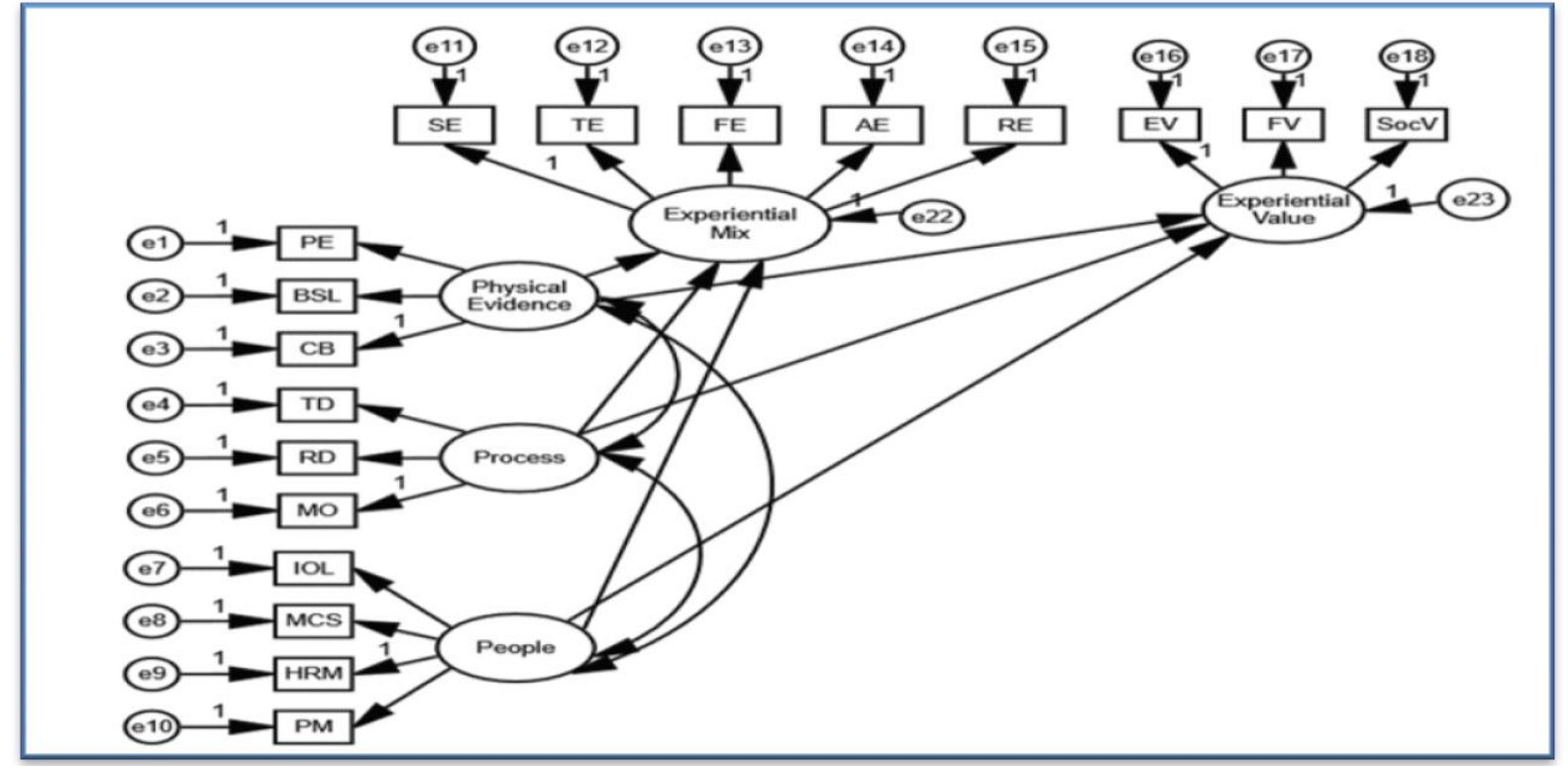

Analysis of Variance (ANOVA, and Multiple Comparisons): ANOVA was used to investigate whether or not selected respondent profile variables (i.e. age, education, region, and preferred choice of network operator) have a significant effect on the mobile mix (i.e. the physical evidence, processes, and people). It must be noted that the factor analysis retained all the variables in the mobile mix and the CX dimensions assembled in one factor, therefore all the variables were included in the analysis. The results for ANOVA and T-Test are summarised in Tables 1 and 2.

Table 1: ANOVA Results on Mobile Mix

\begin{tabular}{lcccccc}
\hline $\begin{array}{l}\text { Independent } \\
\text { Variables }\end{array}$ & \multicolumn{3}{c}{ Dependent Variables (Mobile Mix) } \\
& \multicolumn{3}{c}{ Physical Evidence } & \multicolumn{2}{c}{ Processes } & \multicolumn{2}{c}{ People } \\
\hline & F-value & p-value & F-value & p-value & F-value & p-value \\
Age & & & & & & \\
Education & 7.469 & $0.00^{* *}$ & 6.251 & $0.00^{* *}$ & 5.202 & $0.002^{*}$ \\
Region & 8.615 & $0.00^{* *}$ & 6.973 & $0.00^{* *}$ & 7.424 & $0.000^{*}$ \\
Preferred network operator & 1.58 & 0.119 & 1.322 & 0.218 & 1.382 & 0.192 \\
\hline
\end{tabular}

$\left({ }^{*} \mathrm{p}<0.05 ;{ }^{* *} \mathrm{p}<0.001\right.$

The ANOVA test as displayed in Table 1 found a significant difference within the mobile mix factors for the demographic variables. According to Hair et al. (2014) for a better understanding and measure of differences through ANOVA, in an ideal situation, the significant (Sig.) value must be less than 0.05 . The 0.05 indicates that between some of the groups of the demographic variables, there is a significant difference. Also, where the Sig. value shows a greater number than 0.05 , there is no significant difference. The ANOVA results regarding the influence of age, education, region and currently preferred network operator variables on the mobile mix indicated that with age, $\mathrm{f}=7.733, \mathrm{df}=3$, and $\mathrm{p}$-value $=0$ between groups. Therefore, a significant difference between the age groups on the mobile mix was found in the study. In addition, the results from the Tukey HSD (t-test) comparison of age groups showed the following values between age groups 19-30 and 4150 , as well as $19-30$ and 51-59, were Sig $=0$ and Sig=0,026, respectively. These indicate values less than the 0.05 threshold, therefore, confirming the significant differences in the views of these age groups regarding the mobile mix. Also, a difference was found between age groups 31-40 and 41-50, 41-50 and 19-30, 31-40 and 51-59, as well as 41-50 and 31-40, with respective Sig. values of $0.044,0,0.0256$, and 0.048 . The age groups 
51-59 and 19-30 also discovered a significant difference between the groups, with Sig=0.026; smaller than the 0.05 threshold.

The significant relationships between the age groups concerning the mobile mix indicated that there were different views amongst the age groups. It must be noted that some age groups reported no significant differences. Thus, the ANOVA test result between age groups 19-30 and 31-40, 31-40 and 19-30, 41-50 and 51-59, as well as 51-59 and 41-50, reported Sig. values larger than the 0.05 threshold. These were with the Sig values $0.381,0.381,1$, and 1 , respectively. The results from these age groups indicate that significant differences between the age groups on the mobile mix did not exist. As a result, those age groups share the same opinions and views with regard to the mobile mix. The ANOVA test between education level and the mobile mix was also conducted. The following values were discovered $f=9.789, d f=4$, and $p$-value $=0$. These results showed significant differences between education and the mobile mix in the study. The t-test comparison result also indicated that the Sig. values of the mobile mix for the education levels were primary school and certificate/diploma/degree level Sig=0.001; high school and certificate/diploma/degree level Sig=0; certificate/diploma/degree and primary school Sig=0.001; certificate/diploma/degree and high school Sig=0; as well as certificate/diploma/degree and post-graduate qualification Sig=0.003. These resulted in a smaller value than the required threshold of 0.05 .

The ANOVA test found a significant difference between average scores, showing that the views and opinions of these educational qualification levels on the mobile mix were different from each other. Nevertheless, there was no significance between the following levels of education on the mobile mix: no schooling and primary school, no schooling and high school, no schooling and certificate/diploma/degree, and no schooling and post-graduate qualification with Sig. values involving, 0.945, 0.946, 0.174, and 1, respectively.There was also no significant difference between primary school and no schooling, high school, and post-graduate qualification, as all the Sig. values were beyond the threshold of 0.05 . As a result, the ANOVA test showed that the opinions and views from these educational levels supported the mobile mix. Lastly, an ANOVA test concerning the difference between the preferred network operator and the mobile mix was conducted. The following results were discovered: $\mathrm{f}=2.917, \mathrm{df}=4$, and $\mathrm{p}$-value $=0.021$, as displayed in Table 1 . These results indicated that no significant differences were found between average scores of the currently preferred network operator categories to the mobile mix in the study. Further, to confirm these results, the t-test comparison was conducted, and the results were: between MTN and Vodafone, Sig=0.129; between MTN and Airtel, Sig=0.057; between MTN and TIGO, Sig=0.847; and between MTN and GLO, Sig=0.469. Also, between Vodafone and Airtel, Sig=0.915; between Vodafone and TIGO, Sig=0.995; between Vodafone and GLO, Sig=0.957; between Airtel and TIGO, Sig=0.861; between Airtel and GLO, Sig=1; and between TIGO and GLO, $\mathrm{Sig}=0.911$. These outcomes show that there was no significant difference between the average scores of these groups concerning the mobile mix. The values derived were all greater than 0.05 . It, therefore, indicates that the customers within the preferred network operator groups shared the same opinions on the mobile mix.

Post-Hoc Tukey Test (T-Test): The post-hoc analysis for the mobile mix factor, with the associated subvariables physical evidence: PE, BSL and CB; process: TD, RD, and MO; and people: IOL, MCS, HRM, and PM were conducted. The Post-hoc Turkey test is more useful than the ANOVA test result which only discovers and concentrates on the statistical significance of a study. The t-test results of the gender profile regarding male and female to the mobile mix and its sub-variables were analyzed. The result of the test is displayed in Table 2 . 


\begin{tabular}{l} 
Journal of Economics and Behavioral Studies (ISSN: 2220-6140) \\
Vol. 13, No. 2, pp. 34-44, April 2021 \\
\hline \hline
\end{tabular}

Table 2: T-Test Result on Mobile Mix

Levene's Test for
Equality of Variances

\begin{tabular}{|c|c|c|c|c|c|c|}
\hline & $\mathbf{F}$ & Sig. & $\mathbf{t}$ & Df & Sig. (2-tailed) & $\begin{array}{l}\text { Mean } \\
\text { Difference }\end{array}$ \\
\hline \multirow[t]{2}{*}{$\mathrm{PE}$} & 4.863 & 0.028 & -0.548 & 412 & 0.584 & -0.03637 \\
\hline & & & -0.552 & 411.529 & 0.581 & -0.03637 \\
\hline \multirow[t]{2}{*}{ BSL } & 2.403 & 0.122 & -1.348 & 412 & 0.178 & -0.07807 \\
\hline & & & -1.355 & 411.948 & 0.176 & -0.07807 \\
\hline \multirow[t]{2}{*}{ CB } & 0.010 & 0.920 & -0.082 & 412 & 0.935 & -0.00449 \\
\hline & & & -0.082 & 407.886 & 0.935 & -0.00449 \\
\hline \multirow[t]{2}{*}{ Physical Evidence } & 2.027 & 0.155 & -0.751 & 412 & 0.453 & -0.03964 \\
\hline & & & -0.753 & 411.478 & 0.452 & -0.03964 \\
\hline \multirow[t]{2}{*}{ TD } & 3.442 & 0.064 & -1.335 & 412 & 0.183 & -0.06413 \\
\hline & & & -1.342 & 411.985 & 0.180 & -0.06413 \\
\hline \multirow[t]{2}{*}{$\mathrm{RD}$} & 4.116 & 0.043 & 0.524 & 412 & 0.601 & 0.02803 \\
\hline & & & 0.524 & 408.884 & 0.600 & 0.02803 \\
\hline \multirow[t]{2}{*}{ MO } & 3.068 & 0.081 & -0.036 & 412 & 0.972 & -0.00176 \\
\hline & & & -0.036 & 411.818 & 0.971 & -0.00176 \\
\hline \multirow[t]{2}{*}{ Process } & 4.402 & 0.037 & -0.287 & 412 & 0.774 & -0.01262 \\
\hline & & & -0.288 & 411.787 & 0.773 & -0.01262 \\
\hline \multirow[t]{2}{*}{ IOL } & 3.389 & 0.066 & -1.416 & 412 & 0.157 & -0.06895 \\
\hline & & & -1.429 & 410.742 & 0.154 & -0.06895 \\
\hline \multirow[t]{2}{*}{ MCS } & 0.639 & 0.425 & -0.558 & 412 & 0.577 & -0.02990 \\
\hline & & & -0.559 & 410.384 & 0.576 & -0.02990 \\
\hline \multirow[t]{2}{*}{ HRM } & 1.734 & 0.189 & -1.150 & 412 & 0.251 & -0.06242 \\
\hline & & & -1.156 & 411.969 & 0.248 & -0.06242 \\
\hline \multirow[t]{2}{*}{ PM } & 6.869 & 0.009 & -1.030 & 412 & 0.304 & -0.05042 \\
\hline & & & -1.043 & 405.178 & 0.298 & -0.05042 \\
\hline \multirow[t]{2}{*}{ People } & 5.263 & 0.022 & -1.233 & 412 & 0.218 & -0.05292 \\
\hline & & & -1.241 & 411.930 & 0.215 & -0.05292 \\
\hline \multirow[t]{2}{*}{ Mobile Mix } & 4.309 & 0.039 & -0.852 & 412 & 0.395 & -0.03506 \\
\hline & & & -0.856 & 411.852 & 0.393 & -0.03506 \\
\hline
\end{tabular}

The equality of variance for the mobile mix component thephysical evidence and its sub-variables PE, BSL, and CB indicated the following results:physical evidence $(\mathrm{t}=-0.751, \mathrm{df}=412, \mathrm{p}$-value $=0.453), \mathrm{PE}(\mathrm{t}=-0.548$, $\mathrm{df}=412$, $\mathrm{p}$-value $=0.584)$, BSL $(\mathrm{t}=-1.348, \mathrm{df}=412, \mathrm{p}$-value $=0.178)$, and $\mathrm{CB}(\mathrm{t}=-0.082, \mathrm{df}=412$, $\mathrm{p}$-value $=$ 0.935). These weregreater than the 0.05 ; therefore, the values for these variables concerning men and woman did not differ significantly. Based on these results, the average scores of physical evidence, PE, BSL, and CB for the gendergroups were found to not be significantly different. The result also implies that the men and women in the study had significantly similar opinions on the factors. Also, the test for equality of variances for process and its sub-variables TD, $\mathrm{RD}$ and MO, discovered the following: process $(\mathrm{t}=-0.287, \mathrm{df}=412, \mathrm{p}$-value $=$ 0.774), $\mathrm{TD}(\mathrm{t}=-1.335, \mathrm{df}=412, \mathrm{p}$-value $=0.183), \mathrm{RD}(\mathrm{t}=-0.524, \mathrm{df}=412, \mathrm{p}$-value $=0.601)$, and $\mathrm{MO}(\mathrm{t}=-$ $0.036, \mathrm{df}=412$, $\mathrm{p}$-value $=0.972$ ). These results denote that the values of process and its sub-variables were greater than 0.05 ; therefore, the average values for the factors and their relation to the respective gender categories did not differ significantly. 
Consequently, the female and male groups had similar opinions regarding the variables. On the other hand, people and its sub-variables also discovered the following values in the $\mathrm{t}$-test result: people $\mathrm{t}=-1.233, \mathrm{df}=$ 412, $\mathrm{p}$-value $=0.218)$, IOL $(\mathrm{t}=-1.416, \mathrm{df}=412, \mathrm{p}$-value $=0.152), \mathrm{MCS}(\mathrm{t}=-0.558, \mathrm{df}=412, \mathrm{p}$-value $=0.577)$, $\operatorname{HRM}(\mathrm{t}=-1.150, \mathrm{df}=412, \mathrm{p}$-value $=0.251)$, and PM $(\mathrm{t}=-1.030, \mathrm{df}=412, \mathrm{p}$-value $=0.304)$. These $\mathrm{t}$-test results for the people and its sub-variables IOL, MCS, HRM, and PM indicate that the opinions of men and women did not differ significantly from each other, since the p-values were larger than 0.05 . Therefore, the female and male respondents had similar opinions on the factors in the study. In totality, the mobile mix in the study obtained the following $\mathrm{t}$-test result in the study $(\mathrm{t}=-0.852, \mathrm{df}=412$, $\mathrm{p}$-value $=0.395)$. This result shows a $\mathrm{p}$ value larger than the threshold 0.05 . In this manner, both gender groups in the study had overall similar opinions with regard to the mobile mix.

\section{Conclusion, Recommendations and Managerial Implications}

Conclusion: In conclusion, through this study, the network operators in Ghana, businesses and relevant policy-makers gained insight into how integrating the mobile mix components and its sub-variables will facilitate the building of positive customer experiences. Consequently, the management and role players of these organizations must be cognisant of the study's results and practical recommendations during future strategy and tactical development as well as the implementation. The results, conclusions and recommendations of this study indicate that the integrating of the mobile mix components could increase positive customer experience, thereby; facilitating customers' loyalty, increase in sales and profitability, as well as positive word of mouth advertisement.

Recommendations and Managerial Implications: Positive customer experiences are important to organizations worldwide. A number of managerial implications and recommendations with regard to the mobile mix and customer experience were made.

- Organizations must keep their environment tidy and clean.

- The architectural designs of the buildings of organizations should be attractive and well decorated and proper ventilation must be provided to customers.

- The signs, logos, uniforms of staff members, gifts and the entire corporate brand must be attractive to inspire a positive customer experience.

- Organizations should invest more in research and development in order to conduct proper needs assessments of their customers' preferences and tastes.

- Organizations should provide awards and recognition systems to their workforce to inspire them to provide good and friendly services to customers, thereby facilitating a positive customer experience.

The empirical results revealed a significant positive relationship between the mobile mix and customer experience. The results of this study show that where customers derive positive experience from their physical evidence, processes and people they are attracted to the organizations. Therefore, the following recommendations are made.

- Organizations must try as much as possible to design customer experience programs and campaigns that appeal to the five senses of customers successfully.

- Organizations should uniquely design and distinguish their physical evidence, processes and people elements from competitors to offer positive acts, think, sense, feel, and relate experiences to customers.

Limitations and Direction for Future Research: This research faced a limitation. It was found that about half of the respondents were between the ages of 19 and 30 years, which might have skewed the results to a limited extent. Due to this limitation, the results of this research should be generalized with caution, and it is suggested that future studies should strive to obtain the views and opinions of more equally distributed age groups. Despite the above limitation, a reliable measuring instrument can be employed by organizations. Views and opinions from the customers of the five registered mobile network operators in Ghana were 
gathered. Other studies might want to expand the sampling frame and include policy development and implementation strategies in the measuring instrument.

\section{References}

Adhikari, A. \& Bhattacharya, S. (2016). Appraisal of literature on customer experience in the tourism sector: A review and framework. Current Issues in Tourism, 19(4), 296-321.

Alberg, D. (2014). Experiential Marketing Events - Creating Successful Experiences. Master Thesis. Denmark: Copenhagen Business School.

Alkilani, K., Ling, K. C.\& Abzakh, A. A. (2013). The Impact of Experiential Marketing and Customer Satisfaction on Customer Commitment in the World of Social Networks. Asian Social Science, 9(1), 262-270.

Amoah, F. (2016). Customer satisfaction with the guesthouse experience in Ghana. Port Elizabeth, Eastern Cape, South Africa.

Ananta, B. (2016). Experiential marketing and customer relationship marketing in creating customer value. Customer Survey of 3, 4 and 5-star hotels in the West Java Province, Asia Tourism Forum 2016. The 12th Biennial Conference of Hospitality and Tourism Industry in Asia (ATF-16). Indonesia: Atlantis Press.

Bhattacharya, P. (2016). Identifying Four Key Means of Business Value Creation using Enterprise Systems: An Empirical Study. Journal of International Technology and Information Management, 25(1), 19-38.

Bilgihan, A., Cobanoglu, C. \& Collins, G.R. (2014). Hospitality information technology. Iowa: Kendall/Hunt.

Bounds, M., Mallgee, R., Mayhew, W.\& Van Deventer, L. (2011). Focus business Studies; Learners book Grade 10. Cape Town: Maskew Miller Longman.

Bricci, L., Fragata, A.\& Antunes, J. (2016). The Effects of Trust, Commitment and Satisfaction on Customer Loyalty in the Distribution Sector. Journal of Economics, Business and Management, 4(2), 173-177.

Cambra-Fierro, J., Gao, L. X., Melero-Polo, I.\& Trifu, A. (2021). How do firms handle variability in customer experience? A dynamic approach to better understanding customer retention. Journal of Retailing and Consumer Services, 102578.

Conti, E. \& Peachlivanidou, I. (2016). Experiential marketing and cultural route: The Case Study of the Routes of the Olive Tree. Master Thesis. Denmark: Aalborg University.

Cuellar, S. S., Eyler, R. C.\& Fanti, R. (2015). Experiential Marketing and Long-Term Sales. Journal of Travel \& Tourism Marketing, 32(5), 534-553.

Danquah, C. (2018). Why NCA fined 4 Telcos gh $\$ 34$ million for poor services. Retrieved 06 20, 2019, from http://ghananews360.com/why-nca-fined-4-telcos-gh\%C2\%A234-million-for-poor-services/.

Datta, V. (2017). A Conceptual Study of Experiential Marketing: Importance, Strategic Issues and Its Impact. International Journal of Research-Granthaalayah, 5(7), 26-30.

De Keyser, A., Verleye, K., Lemon, N. K., Keiningham, T. L.\& Klaus, P. (2020). Moving the Customer Experience Field Forward: Introducing the Touchpoints, Context, Qualities (TCQ) Nomenclature. Journal of Service Research, 1-77.

Diebner, R., Silliman, E., Ungerman, K.\& Vancauwenberghe, M. (2020). Adapting customer experience in the time of coronavirus. Mckinsey and Company.

Duncan, E. (2017). Customer experience: New capabilities, new audiences, and new opportunities, Number 2, June 2017, McKinsey \& Company.

Ehlers, T. \& Lazenby, K. (2010). Strategic Management; South African concepts and cases. 3rd ed. Van Schaik Publishers.

Farshad, M., Kwek, C. L.\& Amir, N. (2012). Exploring the Relationship between Experiential Marketing and Experiential Value in the Smartphone Industry. International Business Research, 5(11), 169-177.

Gao, W., Fan, H., Li, W.\& Wang, H. (2021). Crafting the customer experience in omnichannel contexts: The role of channel integration. Journal of Business Research, 126,122-22.

Gita, S. H. (2017). Experiential Marketing Creative Antecedence for Success of Brand Loyalty (A Study on the Users of Perfume for Body in Indonesia). international review of Management and Marketing, 7(1), 529-536.

Grundey, D. (2008). Experiential Marketing vs Traditional Marketing: Creating Rational and Emotional Liaisons with Consumers. The Romanian Economic Journal, 11(29), 133-155.

Gurel, C., Orhan, A. \& Fazil, K. (2014). Components of Experiential Value: Case of Hospitality Industry. Procedia - Social and Behavioral Sciences, 150(10), 1040-1049. 
Hair, J. F., Black, W. C., Babin, B. J.\& Anderson, R. E. (2014). Multivariate data analysis. Essex: Pearson Education Limited.

Helen, P., Adrian P., Martin, C.\& Moira, C. (1999). Relationship Marketing for Competitive Advantage. Winning and Keeping Customers. The Chartered Institute of Marketing. Butterworth-Heinemann.

Jauhari, V. \& Dutta, K. (2010). Services: Marketing, operations, and management. New Delhi, India: Oxford University Press.

Kalbach, J. (2016). Mapping experiences: A complete guide to creating value through journeys, blueprints and diagrams. Sebastopol: O'Reilly.

Keiningham, T., Aksoy, L., Bruce, H.L., Cadet, F., Clennell, N., Hodgkinson, I. R. \& Kearney, T. (2020). Customer experience-driven business model innovation. Journal of Business Research, 116, 431-440.

Krishna, A. \& Schwarz, N. (2014). Sensory Marketing, Embodiment, and Grounded Cognition: A Review and Introduction. Journal of Consumer Psychology,20(10), 30-36.

Lockwood, D. (2017). Great Examples of Experiential Marketing. Retrieved 12 21, 2017, from https://www.boldcontentvideo.com/2017/11/21/great-examples-of-experiential-marketing/.

Lacoma, T. (2018). The advantages of Research and Development Business Strategies. Retrieved 02 12, 2018, from http://smallbusiness.chron.com/advantages-research-development-business strategies21246.html.

Lovelock, C. \& Wirtz, J. (2011). Services Marketing; People, Technology, Strategy (7th Ed). Pearson Education Publishing. Prentice-Hall, London.

Mehmetoglu, M. \& Engen, M. (2011). Pine and Gilmore's concept of the experience economy and its dimensions: An empirical examination in tourism. Journal of Quality Assurance in Hospitality and Tourism, 12, 237-255.

Morgan, B. (2017). What is customer experience? Retrieved 6 6, 2020, from https://www.forbes.com/sites/blakemorgan/2017/04/20/what-is-customer-experience2/\#7e877f670c2b.

National Communications Authority. (2019). Telecom Voice Subscription. Retrieved 6 24, 2019, from https://nca.org.gh/industry-data-2/market-share-statistics-2/voice-2/.

Same, S. (2014). Experience Marketing in Country Branding: Theoretical Developments and an Estonian Case Study. Research in Economics and Business: Central and Eastern Europe, 6(1), 65-88.

Saunders, M., Lewis, P., \& Thornhill, A. (2016). Research Methods for Business Students (7th ed). United Kindom: Pearson Education.

Schmitt, B. (2010). Experience Marketing: Concepts, Frameworks and Consumer Insights. Foundation and Trends in Marketing, 5(2), 55-112.

Schmitt, B. (1999a ). Experiential Marketing. Journal of Marketing Management, 15(1-3), 53-67.

Schmitt, B. (1999b).Experiential Marketing: How to Get Customers to Sense, Feel, Think, Act, and Relate to Your Company and Brands. New York: The Free Press.

Shukla, T. (2007). Experiential Marketing. The New Paradigm. Indian Journal of Marketing, 4, 10-12.

Smilansky, S. (2009).Experiential marketing: A Practical Guide to Interactive Brand Experiences. London: Kogan Page.

Sundbo, J. \& Darmer, P. (2008). Creating experiences in the experience economy. Cheltenham: Edward Elgar.

Ullar, G.M.S. \& Islam, M.R. (2011). Factors Influencing Consumer Service Experience in Private Hospitals: A study from Bangladeshi Perspective. Interdisciplinary Journal of Contemporary Research in Business, 3(5), 138-147.

Wibowo, A., Chen, S., Wiagin, U., Ma, Y. \& Ruangkanjanases, A. (2021). Customer Behavior as an Outcome of Social Media Marketing: The Role of Social Media Marketing Activity and Customer Experience. Sustainability, 13, 189.

Yiadom, M. B. (2019). Creating value through experiential marketing for mobile network operators in Ghana. Ph.D. Thesis. Port Elizabeth, Eastern Cape, South Africa: Nelson Mandela University. 